\title{
Assessment Genetic Mutations in Genes ACE, AGT, AGTR1, REN in Indicate Twin-to-Twin Transfusion Syndrome
}

\section{Shahin A*, Reza H, Hossein A and Mohammadreza A \\ Division of Medical Genetics and Molecular Pathology Research, Iran}

${ }^{*}$ Corresponding author: Shahin Asadi, Director of the Division of Medical Genetics and Molecular Research, Tabriz, Iran, Tel: +989379923364; Email:

\section{Review Article \\ Volume 4 Issue 1}

Received Date: January 10, 2019

Published Date: January 31, 2019 shahin.asadi1985@gmail.com

\section{Abstract}

TTT syndrome, also known as kidney dysgenesis, is a severe and severe renal disorder characterized by abnormal kidney development before birth. Specifically, renal structures called "proximal tubules" are either not present or undeveloped in the TTT syndrome. TTT syndrome can be caused by mutations of ACE, AGT, AGTR1, and REN genes.

Keywords: TTT syndrome; Mutations of ACE, AGT, AGTR1, and REN genes

\section{Generalizations of TTT Syndrome}

TTT syndrome, also known as kidney dysgenesis, is a severe and severe renal disorder characterized by abnormal kidney development before birth. Specifically, renal structures called "proximal tubules" are either not present or undeveloped in the TTT syndrome. These structures help to restore nutrients, water and other materials to the blood and transfer everything to the urine. Without proximal tubules, the kidneys cannot produce urine (anurysm) [1] (Figure 1).

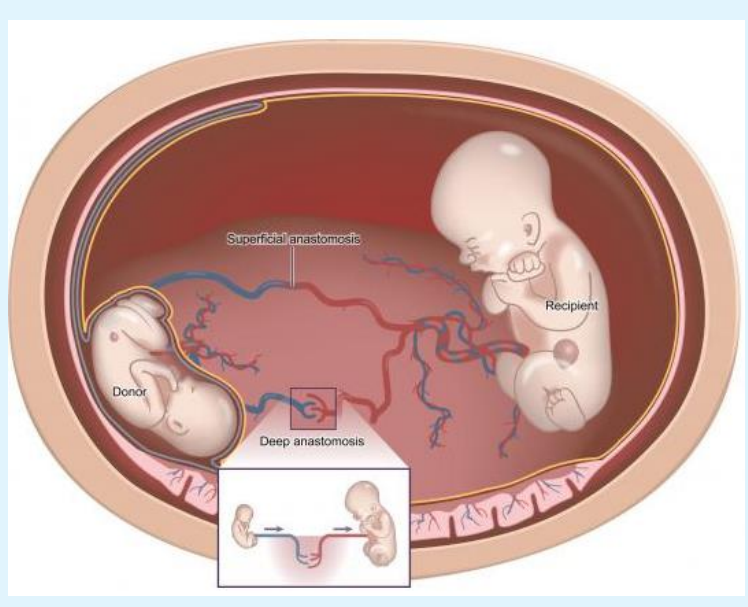

Figure 1: Schematic of twin-twin blood transfusion (TTT syndrome). 


\section{Pediatrics \& Neonatal Biology Open Access}

\section{Symptoms of TTT Syndrome}

The urine of the embryo is the main component of the fluid called amniotic fluid that surrounds the embryo and anuria leads to a decrease in the level of amniotic fluid (oligohydramnios). Amniotic fluid protects the fetus from potential injuries and plays an important role in many organs, including lungs. Lowering the level of amniotic fluid causes a number of disorders called the Potter Sequence, which includes distinct facial features such as flat and large nose, low ears, excess skin on the hips and lungs [2] (Figure 2).

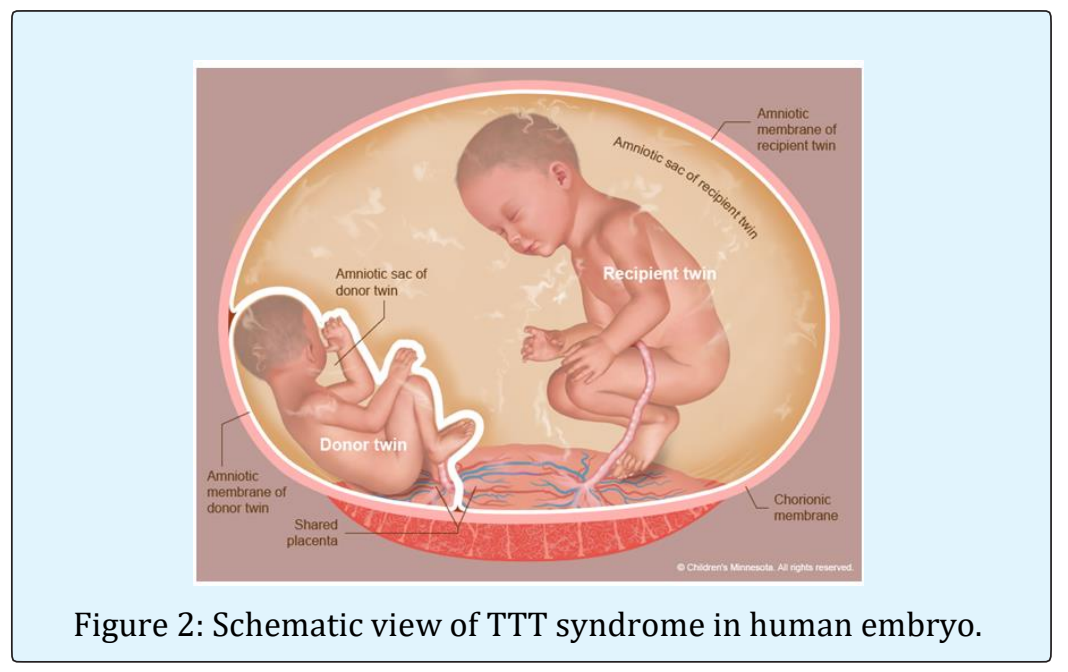

TTT syndrome also reduces blood pressure (hypotension). In addition, the development of skull bones in some affected individuals is abnormal, creating a large amount of space between the skull bones. People with this syndrome usually die or die before birth, or shortly after birth due to respiratory failure. People with

this syndrome can rarely survive until childhood by applying therapies. The blood pressure of these people is usually normal, but they develop very quickly into chronic kidney disease, which is associated with decreased kidney function and worsens over time [3] (Figure 3).

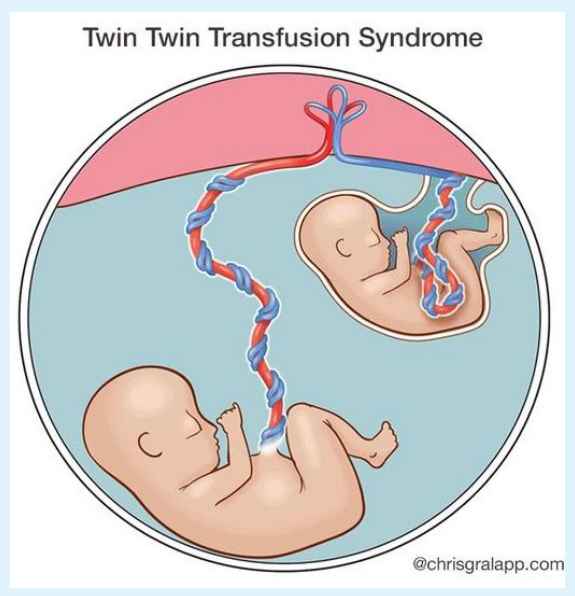

Figure 3: Another schematic of TTT syndrome in human embryos.

\section{Etiology of TTT Syndrome}

TTT syndrome can be caused by mutations of ACE, AGT, AGTR1, and REN genes. The ACE gene is based on the long arm of chromosome 17 as 17q23.3. The AGT gene is based on the long arm of chromosome 1 as 1q42.2. The AGTR1 gene is based on the long arm of chromosome 3 as 3q24. The REN gene is based on the long arm of 


\section{Pediatrics \& Neonatal Biology Open Access}

chromosome 1 as 1q32.1. All of these genes are involved in the renin-angiotensin system, which regulate blood pressure and balance of fluid and salt in the body, and contribute to the development of the kidneys before birth [4] (Figures 4-7).

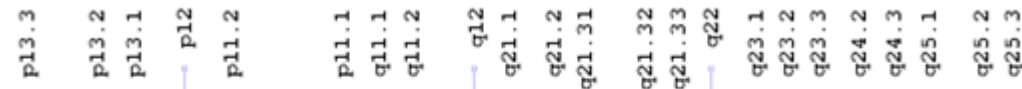

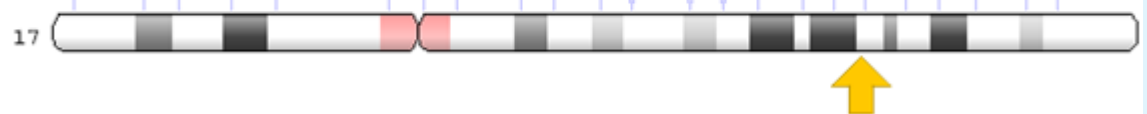

Figure 4: Schematic view of chromosome number 17, where the ACE gene is located in the long arm of this chromosome as $17 \mathrm{q} 23.3$.

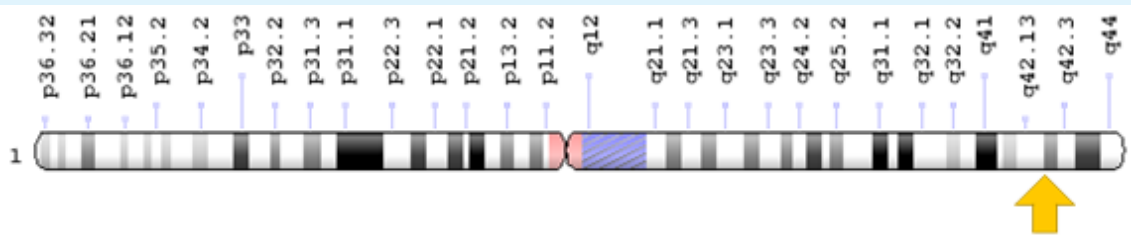

Figure 5: Schematic view of chromosome 1, in which the AGT gene is located in the long arm of this chromosome $1 \mathrm{q} 42.2$.

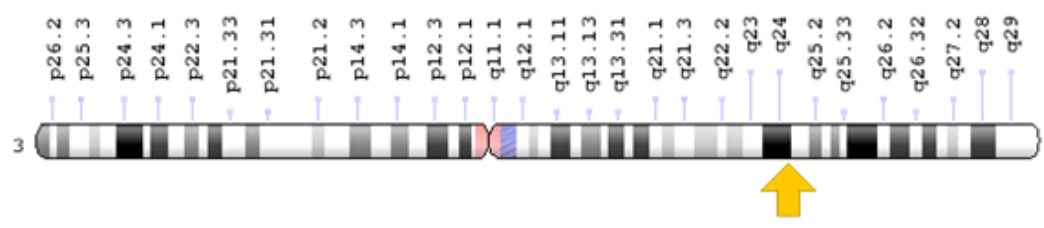

Figure 6: Schematic view of chromosome number 3 where the AGTR1 gene is located in the long arm of this chromosome as $3 \mathrm{q} 24$.

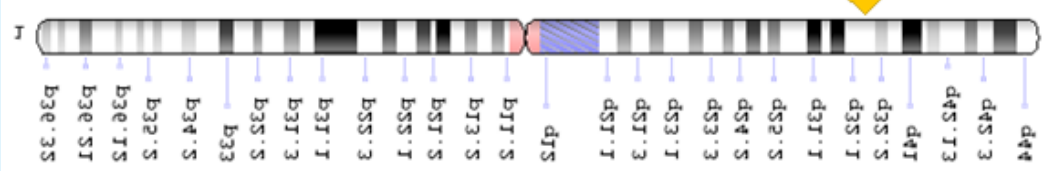

Figure 7: Schematic view of chromosome number 1, in which the REN gene is located in the long arm of this chromosome as $1 \mathrm{q} 32.1$.

The renin-angiotensin system consists of several proteins involved in a series of protein production processes called angiotensin II. In the first step, renin protein (produced from the REN gene) converts a protein called angiotensinogen (produced from the AGT gene) into angiotensin I. In the next step, the angiotensin converting enzyme (produced from the ACE gene) converts angiotensin II into angiotensin II. Angiotensin II then binds to type 1 angiotensin II receptor (AT1 receptor produced from the AGTR1 gene) and stimulates chemical signaling [5].

By binding to the AT1 receptor, angiotensin II stimulates blood vessels and increases blood pressure. This protein also stimulates the production of the aldosterone hormone, which causes the kidneys to absorb salt and water. It is worth noting that increasing the amount of fluid in the body also leads to an increase in 


\section{Pediatrics \& Neonatal Biology Open Access}

blood pressure. The proper blood pressure, which during the growth of the fetus, passes oxygen into the growing tissues, is essential for the normal growth of the kidneys (especially proximal tubules) and other tissues [6].

The mutations in the ACE, AGT, AGTR1, and REN genes decrease the production or decrease of angiotensin II function, which also leads to the inactivation of reninangiotensin system. As a result, the body's active reninangiotensin system, the kidneys cannot control blood pressure. Therefore, since blood pressure has decreased, the blood flow also decreases and embryo tissues do not receive enough oxygen to grow and develop. As a result, the development of the kidneys is impaired, which leads to the characteristics of the TTT syndrome. Reducing blood flow also causes skull abnormalities in people with TTT syndrome [7].

TTT syndrome follows an autosomal recessive hereditary pattern. Therefore, in order to develop this syndrome, two versions of the mutated genes ACE, AGT, AGTR1, REN (one parent and the other mother) are needed and the chance of having a child with TTT syndrome in an autosomal recessive state, for each possible pregnancy $25 \%$ [8] (Figure 8).

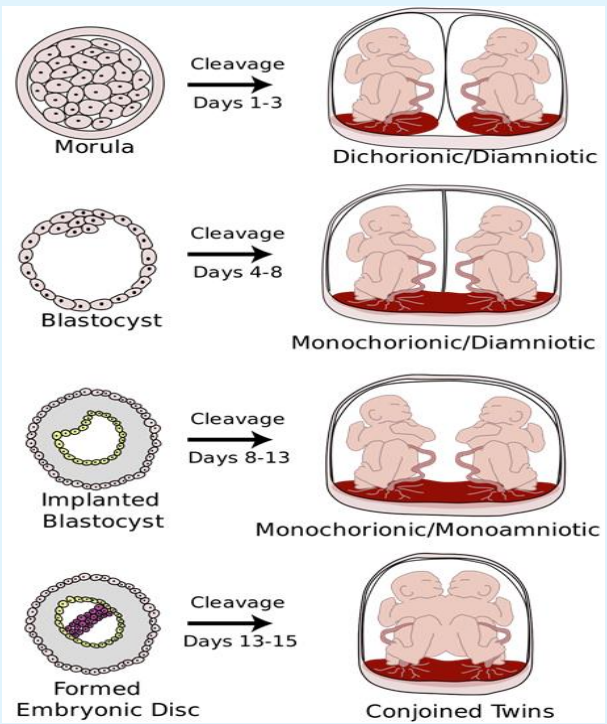

Figure 8: Schematic view of the penetration and fusion stages of twin embryos with TTT syndrome.

\section{Frequency of TTT Syndrome}

TTT syndrome is a rare genetic disorder whose frequency is not known in the world [9] (Figure 1).

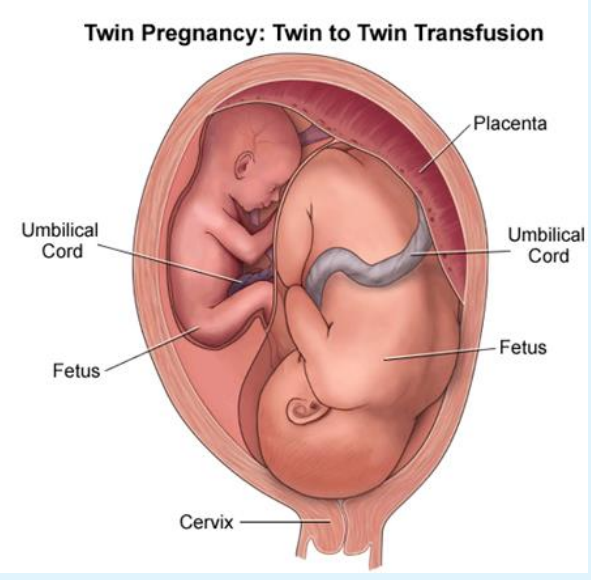

Figure 9: Schematic of placement of twin embryos with TTT syndrome in the mother's womb. 


\section{Pediatrics \& Neonatal Biology Open Access}

\section{Diagnosis of TTT Syndrome}

TTT syndrome is diagnosed based on the clinical and physical findings of the patients and some pathological tests. Nephrological tests are effective in detecting TTT syndrome in order to evaluate kidney function. The only way to detect TTT syndrome is to test the genetic gene of the ACE, AGT, AGTR1, and REN genes to investigate the presence of possible mutations. Prenatal diagnosis is also possible by using the PGD technique and amniocentesis fluid, or by sampling the embryo's chorionic pelvis [10] (Figure 10).

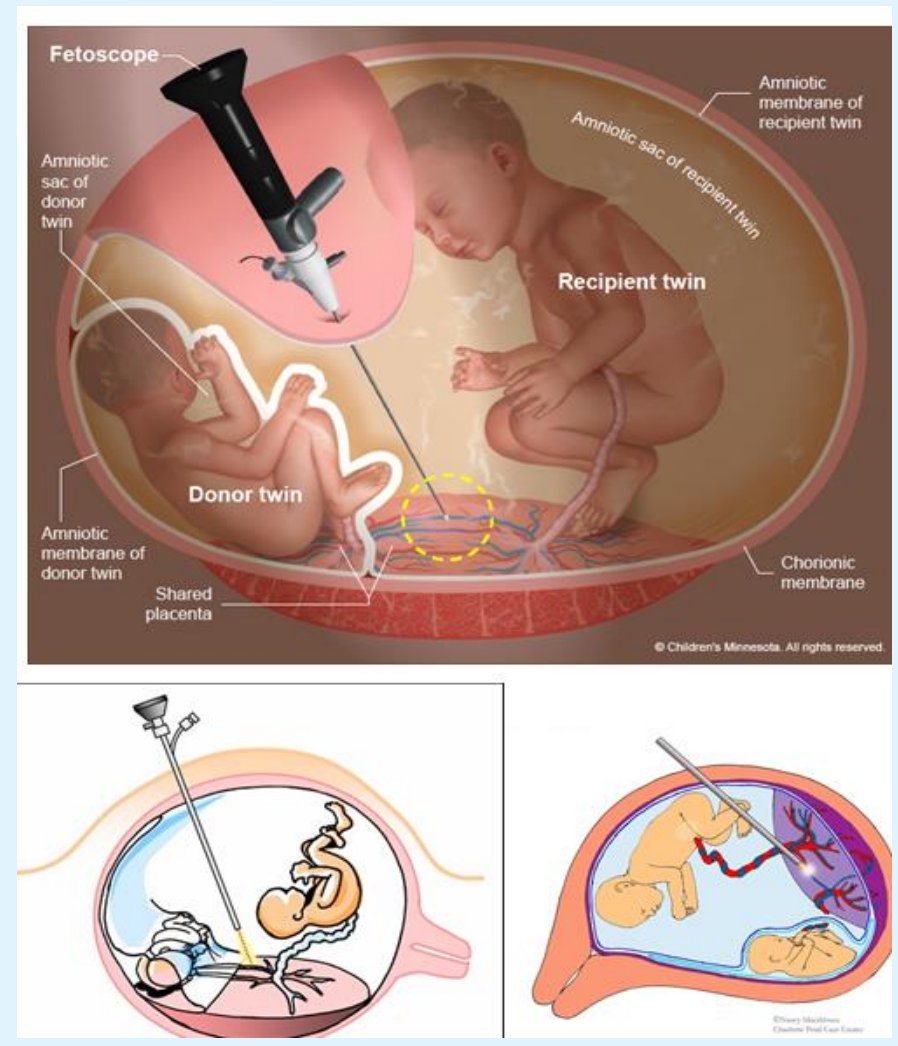

Figure 10: Schematic view of how to fetoscope for twin embryos with TTT syndrome.

\section{TTT Syndrome Treatment Routes}

The TTT syndrome treatment and management strategy is symptomatic and supportive. Treatment may be done by a team of specialists, including pediatricians, nephrologists, hematologists, pulmonary specialists, and other healthcare professionals. Drugs that block the activity of the enzyme blocking angiotensin converting enzyme or AT1 receptor are used to treat high blood pressure. Since these drugs disrupt the renin-angiotensin system, they can potentially cause (non-inherited) TTT syndrome in the embryos used by pregnant mothers. There is no definitive treatment for this syndrome. Genetic counselling is also a special place for all parents who want a healthy baby [10].

\section{Discussion and Conclusion}

TTT syndrome, also known as kidney dysgenesis, is a severe and severe renal disorder characterized by abnormal kidney development before birth. Specifically, renal structures called "proximal tubules" are either not present or undeveloped in the TTT syndrome. TTT syndrome can be caused by mutations of ACE, AGT, AGTR1, and REN genes. Drugs that block the activity of the enzyme blocking angiotensin converting enzyme or AT1 receptor are used to treat high blood pressure (Figures 11-15). 


\section{Pediatrics \& Neonatal Biology Open Access}

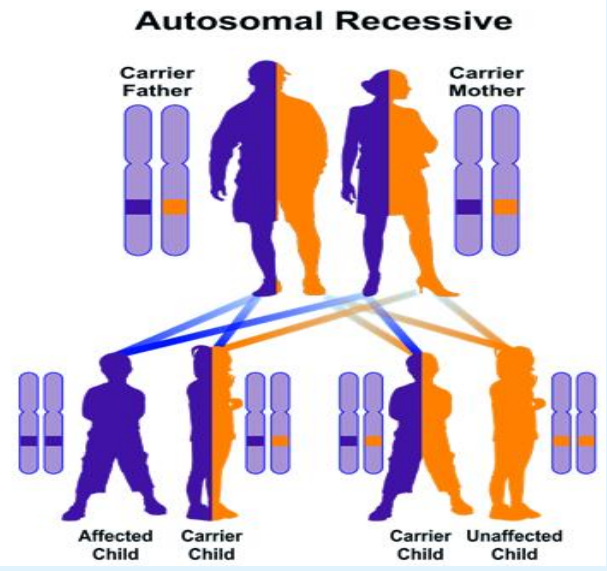

Figure 11: A schematic view of an autosomal recessive hereditary pattern that follows TTT syndrome.

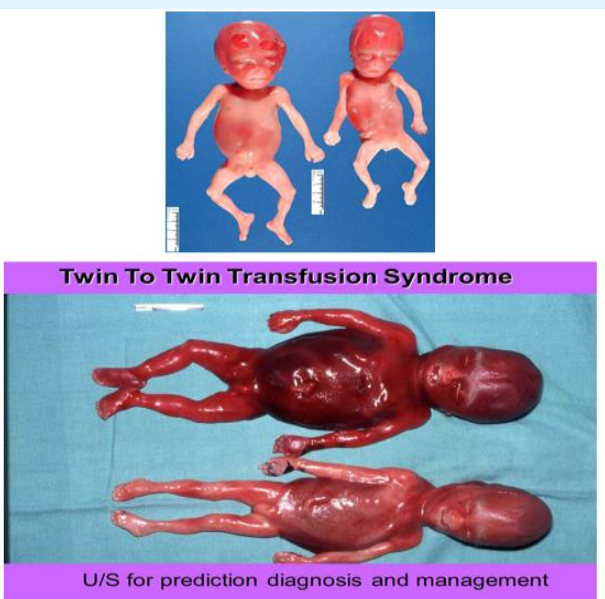

Figure 12: Images of embryos with TTT syndrome associated with related disorders.

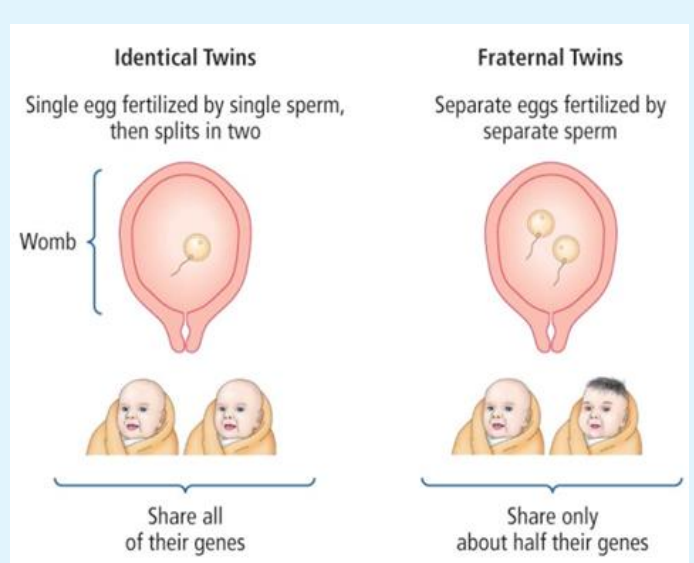

Figure 13: A schematic of single sperm twins containing common genes (left) versus twin sperms that contain half of the common genes (right). 


\section{Pediatrics \& Neonatal Biology Open Access}
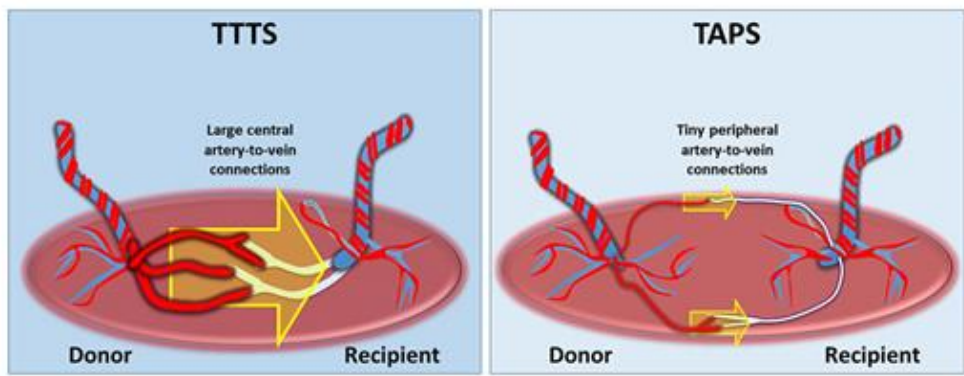

Figure 14: Schematic of the penetration rate (capillary) in normal twins (right) against large blood regression (regimen) in twins with TTT syndrome (left).
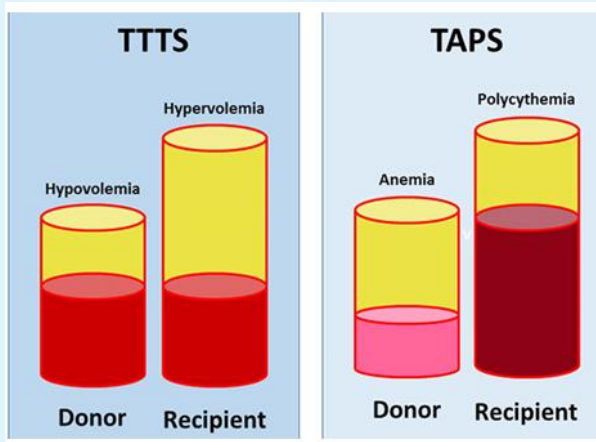

Figure 15: Schematic of blood cell components in twins with TTT syndrome and normal twins.

\section{History of TTT Syndrome}

TTT syndrome was first described in 1875 by Dr. Friedrich Schatz, a gynecologist from Germany (Figure 16).

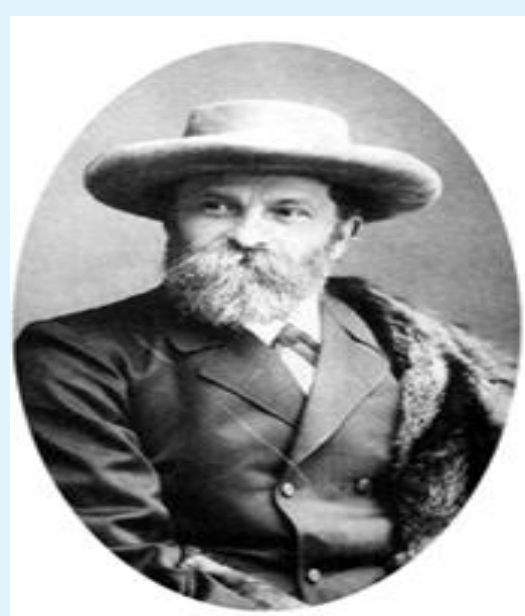

Figure 16: The Image of Dr. Friedrich Schatz Discovered TTT Syndrome in 1875.

\section{References}

1. Gribouval O, Gonzales M, Neuhaus T, Aziza J, Bieth E, et al. (2005) Mutations in genes in the reninangiotensin system are associated with autosomal recessive renal tubular dysgenesis. Nat Genet 37(9): 964-968.

2. Gribouval $\mathrm{O}$, Morinière $\mathrm{V}$, Pawtowski $\mathrm{A}$, Arrondel C, Sallinen SL, et al. (2012) Spectrum of mutations in the renin-angiotensin system genes in autosomal recessive renal tubular dysgenesis. Hum Mutat 33(2): 316-326.

3. Gubler MC, Antignac C (2010) Renin-angiotensin system in kidney development: renal tubular dysgenesis. Kidney Int 77(5): 400-406.

4. Moldavsky M (2009) Renal tubular dysgenesis in Israel: pathologist's experience and literature review. Isr Med Assoc J 11(1): 6-10.

5. Schreiber R, Gubler MC, Gribouval O, Shalev H, Landau D (2010) Inherited renal tubular dysgenesis 


\section{Pediatrics \& Neonatal Biology Open Access}

may not be universally fatal. Pediatr Nephrol 25(12): 2531-2534.

6. Benoit RM, Baschat AA (2014) Twin-to-twin transfusion syndrome: prenatal diagnosis and treatment. Am J Perinatol 31(7): 583-594.

7. Roberts D, Neilson JP, Kilby M, Gates S (2014) Interventions for the treatment of twin-twin transfusion syndrome. Cochrane Database Syst Rev.
8. Slaghekke F, Kist WJ, Oepkes D, Pasman SA, Middeldorp JM, et al. (2010) Twin anemiapolycythemia sequence: diagnostic criteria, classification, perinatal management and outcome. Fetal Diagn Ther 27(4): 181-190.

9. NIH (2011) Twin-to-twin transfusion syndrome Medical Encyclopedia. MedlinePlus.

10. (2012) Twin-Twin Transfusion Syndrome. Children's Hospital Boston. 